\title{
A Conversation with Karen Adelman ${ }^{1}$
}

\author{
INTERVIEWER: JAN WITKOWSKI
}

Cold Spring Harbor Laboratory

\begin{abstract}
Karen Adelman is a Professor of Biological Chemistry and Molecular Pharmacology and Co-Director of the Epigenetics and Gene Dynamics Initiative at Harvard Medical School.
\end{abstract}

Jan Witkowski: The subject of your work [The Integrator Complex] sounds like a wonderful title for a film. What is this 'Integrator'?

Dr. Adelman: It's a very large complex of many proteins - about 14 , at least — and it's actually quite understudied. It was first discovered by Ramin Shiekhattar's lab as something that causes the termination at noncoding RNAs like the snRNAs [small nuclear RNAs]: these are RNA components of the spliceosome. It had been thought to be specific for the snRNAs but as people started to peek into the world of Integrator, it was realized that it in fact does bind other loci. What we've recently started to appreciate is that it binds at protein-coding genes and does much of what it does at these snRNAs. Except at snRNAs, Integrator causes the cleavage of the RNA and termination after just a few hundred nucleotides. That's okay for an snRNA because it's just a few hundred nucleotides long; that's the correct $3^{\prime}$ end. But when it does this at proteincoding genes, that's obviously not the entirety of the protein-coding gene. When it does this, it makes a short transcript that's prematurely terminated and that's nonfunctional, so it's rapidly degraded. What we have is a situation that by studying noncoding RNAs we've learned something new about protein-coding machinery.

Jan Witkowski: Why does it do this? Why does Integrator truncate these - what presumably are going to be quite normal-full-length messages?

Dr. Adelman: This is a fantastic question. This is why we're just at the beginning of understanding what Integrator does. The canonical models for protein-coding gene expression have largely focused on understanding how the polymerase gets brought to the DNA. The process of elongation has been presumed to some extent that-once the polymerase gets started, it goes to the end and then the cleavage and polyadenylation machinery is what takes it off the DNA finally, and that this process of transcription between start and stop is more or less a nonregulated or default pathway.

\footnotetext{
${ }^{1}$ This Conversation covers collaborative work done with Eric Wagner (UTMB Galveston).
}

The question now is: If that's not true, why? Why would the cell evolve such a thing? The answer, of course, is: We don't know. But, you can speculate that when the polymerase initiates transcription and generates a short RNA and then undergoes this step that my lab has studied for many years, this promoter-proximal pausing, it stops in the promoter region associated with this little 20 - to 60 -nt RNA. It sits there, and it waits for a signal to be released into the gene.

There are many reasons you can think of that you wouldn't want that polymerase to stay there forever. One is, because this is a leaky process, you may not want the polymerase to eventually escape and transcribe that gene at a low level. The other is that maybe you just want to get the polymerase off of that gene: if the replication fork is coming through, if you have some kind of stress, or if you have something else where you really want to clear out that region. Having a regulated termination factor that clears the genome of this promoter-proximal polymerase, you could envision many reasons why this would be helpful. We envision it mostly as a way of regulating transcription at a level where, at any moment, you can change your mind. You can tell the polymerase instead of terminating to continue on into the gene, so you can very rapidly upregulate the expression of these genes.

Jan Witkowski: They must be quite carefully controlled, because otherwise Integrator could be chopping things from every transcribed gene.

Dr. Adelman: Absolutely. I think these are some of the exciting questions for the future. In the snRNA example, Integrator is selectively recruited to the snRNAs through interactions - presumably with the SNAPc [snRNA-activating protein complex] protein - with a transcription factor that binds to the start site. That's one level of regulation, which is probably selective recruitment. We're trying to understand what might selectively recruit Integrator to specific protein-coding genes.

At the other level in the snRNAs, there's a sequence in the RNA that's recognized by Integrator. It's called a 3 ' box and, much like the poly(A) site and the canonical cleavage and polyadenylation pathway, it's an AU-rich sequence. When Integrator recognizes it, it seems to stim-

(C) 2019 Adelman. This article is distributed under the terms of the Creative Commons Attribution-NonCommercial License, which permits reuse and redistribution, except for commercial purposes, provided that the original author and source are credited. 
ulate the cleavage activity. What we're looking for now are the transcription factors that bring Integrator to certain protein-coding genes, the sequences within coding genes that may serve the role of this 3 ' box, and then any other levels of regulation that may be figuring into this.

We do know that under different conditions, Integrator can be deployed to different sets of genes. We've looked at the metallothionein genes; this is in collaboration with Jeremy Wilusz. He sees that, under normal conditions when cells are happy, Integrator's not at the metallothionein genes. But when you stimulate metallothionein, Integrator suddenly goes to metallothionein genes and helps to attenuate that response so that it doesn't get out of control. In that situation, it's not meant to keep genes “off" under basal conditions. Rather, it's meant to dampen the expression so that an activation process doesn't cascade too far.

Jan Witkowski: Sort of a fail-safe mechanism.

Dr. Adelman: Exactly.

Jan Witkowski: Does Integrator work at all genes, or is it a particular subset or type of genes?

Dr. Adelman: We see it recruited somewhat selectively to a particular subset of maybe $15 \%-20 \%$ of all active genes in the different conditions and cell types that we've looked at. The work that we've done in Drosophila cells and a limited number of mammalian cells-mouse cells-is consistent with what's been shown in human cells by the Shiekhattar and Benkirane and Pagano labs. It seems to be not at every gene, but it seems to somehow have a subset that it selects. What we find interesting is that that subset can be different in different cell types we've looked at, and under different conditions. I do think that there's a very selective targeting so that you don't have this crazy endonuclease chopping up all the wrong things, but actually going to the places where gene expression should be attenuated.

Jan Witkowski: It could be a monster.

Dr. Adelman: It could be. But the phenomenon, the concept, has been around for decades in the termination processes that we know and love in bacteria.

Jan Witkowski: I was just going to say, is there a similar transcriptional control?

Dr. Adelman: There are terminators and antiterminators. In particular, in the lambda bacteriophage there's a terminator/antiterminator switch in the promoter-proximal region of some of the master regulatory genes. We also know that this process exists in other organisms. In the budding yeast Saccharomyces cerevisiae there's a complex called NNS [Nrd1-Nab3-Sen1] and there too there's an RNA recognition, there's selective recruitment, and there's activity toward both noncoding RNAs and a subset of coding genes. The basic idea that cells use a directed termination is actually out there. It's not something that we are the first to propose. In the mammalian system, this idea that you have regulated promoter-proximal termination has been out there for many years, but to nail down the complex and the conditions where it happens, that's what's exciting and new at this point.

Jan Witkowski: Does that require the development of techniques that were able to do those sorts of experiments?

Dr. Adelman: Absolutely. To be able to separate premature transcription termination from all the subsequent processes of RNA degradation and decay, you need to be looking directly at the nascent transcriptome, to look directly at the nucleotides that are inside the RNA polymerase at any point in time. My lab has developed some techniques, and we've also optimized and used techniques developed by others - like John Lis' lab - to really investigate the nascent transcriptome at single-nucleotide-level resolution.

The data that convinced us we had a handle on what Integrator was doing was the data where we could see at these Integrator-attenuated genes very high levels of polymerase that had gotten onto the promoter, begun transcribing, and then gotten as far as +50 into the gene but didn't make it any farther. Only when we knocked down the Integrator subunits could we then see elongation of the polymerase past that point. That's what really told us that we weren't looking at an RNA stability effect. We weren't looking at something that was posttranscriptional, but we were really looking at a transcriptional cleavage and termination event. Those nascent RNA assays were really essential for being able to understand that.

Jan Witkowski: What's known about how Integrator does it? It's obviously got RNase activity. Did you say how many subunits it is?

Dr. Adelman: The Integrator complex has at least 14 subunits. The field is still trying to understand how these separate into subcomplexes, but clearly there's a subcomplex that contains the Integrator 4, 9, and 11 subunits. Nine and 11 are really interesting, because they're paralogs of two subunits in the normal cleavage and polyadenylation machinery, CPSF [cleavage and polyadenylation specificity factor] 73 and 100. Just like CPSF73 and 100, both proteins have a $\beta$-lactamase domain and a $\beta$-caspase domain, and this gives them the ability to cleave RNA. But, in both Integrator and the normal cleavage and polyadenylation machinery, one of the two subunits is catalytically active and in the other the active site is sort of degraded so that it still can bind to RNA, but it doesn't cleave RNA. You have an auxiliary subunit and the active subunit, and this arrangement is paralleled in the normal cleavage and polyadenylation machinery and in Integrator. A lot of the insights that we have into how Integrator is cleaving really come from the vast literature on these $\beta$-lactamase domains and on the cleavage and polyadenylation machinery.

Jan Witkowski: If I could wave a magic wand for you, what would you really like to know about Integrator?

Dr. Adelman: What I would really like to know about Integrator is very specifically about its targeted recruit- 
ment to certain genes. What we have found is that you can take a gene that has accessible chromatin, all the right histone modifications, transcription factor binding, it brings in the polymerase, and yet if you bring in Integrator too, the gene is not on. The gene's expression is very, very low. If you could imagine a situation - a disease context or a developmental defect - where one gene is aberrantly upregulated, if you could bring Integrator selectively to that gene's promoter or find some key part of Integrator to bring to that gene, you could turn it off in a way that doesn't need to supersede all of the important things that the cell does to activate a gene, but - just at that final step - say, "No, we're going to turn this gene off." I think that would be incredibly powerful, both as a therapeutic approach, but also as a basic biology tool for understanding gene activity.

Jan Witkowski: What happens if you knock Integrator out?

Dr. Adelman: It's lethal. We've been working a lot on really rapid degradation techniques to be able to investigate the effects of knocking out Integrator as soon after getting rid of it as possible. We're moving from RNA interference to degrons to be able to get rid of Integrator within an hour of flipping the switch, because, as I mentioned, Integrator also is responsible for the cleavage of snRNAs. If Integrator is nonfunctional for too long, splicing goes awry and then you end up having lots of issues. We're really trying to find the most fast-acting strategies to, in a targeted way, block Integrator's activity. In particular, we're really interested in blocking the activity of the catalytic subunit and then replacing with mutants that are either lacking the ability to interact with the other subunits or lacking the ability to undergo this catalysis.

When you knock Integrator down, there are a lot of defects. A lot of genes get turned on that shouldn't be on. You can rescue with wild-type Integrator 11, but if you try to rescue with a catalytic-dead Integrator $11 \mathrm{sub}$ unit, not only do those genes' expression not get turned back down, but they actually are further enhanced. It's more like a dominant negative than a rescue. That suggests that you can also form these subcomplexes that co-opt parts of the machinery that presumably - with a 14-subunit complex - does more than just cut the RNA. We're trying to get into fast-acting strategies to pick apart what the other subunits do as well. 


\section{$\$_{\text {CSH\& }}^{\infty}$ Cold Spring Harbor Symposia SYMPOSIA on Quantitative Biology}

\section{A Conversation with Karen Adelman}

Cold Spring Harb Symp Quant Biol published online December 20, 2019

Access the most recent version at doi:10.1101/sqb.2019.84.039008

$\mathbf{P}<\mathbf{P} \quad$ Published online December 20, 2019 in advance of the print journal.

Creative This article is distributed under the terms of the

Commons http://creativecommons.org/licenses/by-nc/4.0/, which permits reuse and

License redistribution, except for commercial purposes, provided that the original author and source are credited.

Email Alerting

Receive free email alerts when new articles cite this article - sign up in Service the box at the top right corner of the article or click here.

Advance online articles have been peer reviewed and accepted for publication but have not yet appeared in the paper journal (edited, typeset versions may be posted when available prior to final publication). Advance online articles are citable and establish publication priority; they are indexed by PubMed from initial publication. Citations to Advance online articles must include the digital object identifier (DOIs) and date of initial publication.

To subscribe to Cold Spring Harbor Symposia on Quantitative Biology go to: http://symposium.cshlp.org/subscriptions 